\title{
Em busca de uma nação brasileira autêntica
}

Izabel Andrade Marson

C APÍTULOS de história do Império reuniu 150 páginas datilografadas de escritos inéditos de Sérgio Buarque de Holanda sobre o período imperial. Em livro organizado por Fernando Antonio Novais, a publicação veio oportunamente somar-se às muitas iniciativas realizadas após a morte de Holanda em 1982, no sentido de reconhecer e valorizar a produção intelectual de um dos mais importantes historiadores brasileiros do século XX.

Os textos foram ordenados em três partes pelo organizador do livro: a primeira agrega quatro capítulos: "Para uma pré-história do Império do Brasil", "A nação e os partidos", "Entre a Liga e o Progresso" e "Por graça de Deus...". A segunda parte traz trecho intitulado "Crise do regime"; e a terceira apresenta dois capítulos sem título. Completam o volume uma nota introdutória do organizador, posfácio de Evaldo Cabral de Melo, cronologia do autor e um índice remissivo.

Tendo em vista atender a previsíveis indagações dos leitores diante de um trabalho inacabado - dentre outras, as motivações dos Capitulos e seu lugar na produção de Sérgio Buarque de Holanda -, a Nota Introdutória informa ser essa "a obra em que Sérgio Buarque se empenhava nos últimos tempos de sua intensa atividade", constituindo "peças de reescritura" de Do Império à República (livro V - Tomo II de O Brasil Monárquico), volume totalmente preparado por ele para a coleção "História Geral da Civilização Brasileira”. Observa que Buarque pretendia desdobrar essa publica- ção (de 1972) em dois livros cujos temas já haviam sido ali anunciados: "O pássaro e a sombra" (onde os inéditos possivelmente se integrariam) e "A Fronda Republicana". Além do percurso intelectual do historiador, suas qualidades e contribuições metodológicas e interpretativas para a história do Império - em especial "a realização em mais alto grau das articulações entre o geral e o particular" -, a nota aponta a problemática que dá unidade ao livro e à obra de Holanda, qual seja, "a persistente [desde Raízes do Brasil] e quase obsessiva indagação - entender por que nos sentimos desterrados em nossa própria terra", isto é, "sondar as estruturas mais profundas do nosso modo de ser, para visualizar as possibilidades de modernização que nos reserva o futuro" (p.9).

Por sua vez, no Posfácio, Evaldo Cabral detalha a intenção do autor de reescrever episódios específicos abordados nos dois primeiros livros de Do Império à República: "A crise do regime" $\mathrm{e}$ "O pássaro e a sombra". Por isso, "revisita acontecimentos e as personagens envolvidas no julho de 1868, em especial a escolha de Pedro II do novo presidente do conselho (Itaboraí) e a intervenção que o embaixador americano pretendeu ter no episódio" (p.227), assim como assuntos mencionados no recuo feito "até os últimos anos de 1850 e aos primeiros de 1860 quando tratou da Conciliação e ascensão ao poder da Liga de conservadores moderados e liberais históricos" (p.227). Dentre as contribuições originais de Do Império à República, agora reiteradas, Evaldo Cabral destaca 
a interpretação sobre a Conciliação, "a primeira manifestação da fobia brasileira pelo sistema de partidos, fobia que desembocará nas tendências militaristas autocráticas dos fundadores da República" (p.229) e, especialmente, a "análise crítica do funcionamento do Império" que enfatiza a "instabilidade das nossas instituições monárquicas [...] disfarçada pelo rodízio incessante dos gabinetes e pelas intervenções diretas do Imperador" e responsável pela inoperância da máquina imperial (p.230). Tal “faina de revisão" não se devia a um "perfeccionismo ocioso", mas à postura e às referências sempre atualizadas do historiador que pretendia "ampliar" e "aprofundar" proposições daquela obra a partir dos dados de "novos trabalhos e pesquisas".

De fato, num cotejamento entre os Capitulos e o texto de Do Império à República, percebe-se que, ao lado dos numerosos livros e fontes que Sérgio Buarque dominava com excepcional destreza (os anais do parlamento, jornais do período e relatos de estrangeiros, por exemplo), aparece arguta exploração de bibliografia mais recente sobre o tráfico e a expansão do café, divulgada nos anos 1970; de trabalhos sobre a história da França e da Inglaterra, de documentação do Arquivo Imperial de Petrópolis, com destaque para registros referidos à "escrita de si", tanto de autoria de Pedro II (seu diário, bilhetes, conselhos à regente, anotações em projetos dos ministros, na biografia do conselheiro Furtado, entre outros) e de sua família, quanto de políticos importantes do Império, a exemplo da correspondência pessoal de Caxias e de Cotegipe.

Tais recursos permitiram ao experiente pesquisador esmiuçar, na longa duração (1822-1870), o funcionamento da máquina administrativa, os bastidores da política imperial, o relacionamento entre os políticos e o imperador e a "personalidade" de Pedro II. Em linguagem clara (onde se mesclam a invejável erudição e refinada ironia características de seu estilo), apesar das interrupções e repetições denotativas da forma inacabada dos textos, Buarque desdobra a argumentação de temas e questões essenciais da história do Império tangenciados em Do Império à República, particularmente a "política de Conciliação", a "Liga Progressista" e a "Crise de 1868". Mas, sobretudo, apresenta análise comparativa entre a experiência imperial brasileira e modelos dos sistemas parlamentares da França e Inglaterra nos meados do XIX para reforçar sua clássica interpretação sobre o parlamentarismo aqui implantado: tratava-se de contraditório amálgama de liberalismo e absolutismo. Ou seja, apesar da "sincronia aproximada" dos eventos europeus e nacionais e das aparências de similitude com os regimes representativos da Europa, de fato, aqui, a monarquia constituiu um pacto político singular que subordinou instituições de cunho liberal ao poder pessoal garantido ao imperador "na letra" da Constituição. Dentre outras, tais evidências testemunhariam a significativa distância do país em relação às instituições inglesas e ao governo de Luís Felipe, e a artificialidade daquelas práticas parlamentaristas no Império.

Reconhecendo ocorrências dessa assertiva na longa duração (1822-1870), em "Para uma pré-história do Império do Brasil", retorna às circunstâncias da independência para identificar no episódio uma associação "entre o arcaico e o moderno", com sensível ênfase no primeiro desses termos. Por um lado, 
denotava um inédito "sentimento nacional" deflagrado pelas medidas restritivas das Cortes (1822), partilhado por vários representantes brasileiros presentes naquela assembleia, embora estimulado mais expressivamente pelas "províncias dissidentes" do Sul. Entretanto, por outro lado, tratava-se de sentimento vivenciado por uma "elite deslumbrada pelo moderno" e sob o "encanto" das ideias da América do Norte mais em decorrência de uma herança colonial que ainda a organizava em núcleos regionais independentes e vínculos com a metrópole caracterizados pela dispersão.

A magnitude dessa força conservadora encaminhou os dirigentes da nova nação para um regime que procurou aproximar a monarquia parlamentar do federalismo. Apesar dos possíveis e conhecidos riscos imbricados nessa opção, Buarque enfatiza que, aqui, ela não representava nenhum perigo em virtude da enorme distância entre os "importadores" e os modelos de origem, e porque "certos temas sacrossantos como os do liberalismo e da democracia formal podiam chegar a ser atraentes, tanto mais quanto ficavam aptos a se converter em verbalizações grandiloqüentes, mas inócuas, já que não tinham por onde ameaçar a ordem estabelecida" (p.22).

A disposição de adaptar instituições estrangeiras sob a égide do "arcaico" se reforçaria no segundo reinado. Por ser a mais importante referência da política monárquica entre a Maioridade e a crise de 1868, a "Conciliação" - uma "réplica indígena da Coalition de 1837", ou uma pretensa adequação do sistema representativo da monarquia de Luís Felipe - é abordada em suas exteriorizações, motivos, suportes e significados. Nos capítulos 2, 3 e 4 que compõem a primeira parte, o autor rememora o percurso daquela invenção política desde o primeiro ensaio em 1844, com a montagem do gabinete híbrido de conservadores e liberais presidido por Macaé, até a crise de 1868 , desencadeada pela substituição do ministério "progressista" de Zacarias de Góis pelo conservador do visconde de Itaboraí. Nas segunda e terceira partes, sinaliza as decorrências dessa inversão e das intervenções do poder pessoal de Pedro II no funcionamento de um "parlamentarismo sem jaça” (p.69), em especial as consequências mais graves da instabilidade política provinda da "dança de gabinetes".

A nação e os partidos historia a constituição, os sucessos e fracassos dos ministérios que praticaram, ou tentaram praticar, a "Conciliação" entre 1853 e 1862 - Paraná (1853-1856), Olinda-Souza Franco (1856-1858), Abaeté (18581859), Muniz Ferraz (1859-1860) e Caxias (1861-1862). O intuito, nesse momento, é esclarecer procedimentos daquela estratégia política arquitetada (e utilizada) por alguns estadistas com a colaboração de Pedro II, destacando-se o empenho em aliciar liberais moderados e, sobretudo, parlamentares de grei conservadora, visando modelar Câmaras obedientes e impedir o avanço de grupos com veleidades jacobinas. Dentre as motivações desse expediente representativo artificial, anota-se a dificuldade das oligarquias em lidar com confrontos entre facções e a organização de partidos, e o receio das turbulências políticas experimentadas durante as regências. Também, a vontade imperial de opinar em todos assuntos políticos e administrativos porque, muito mais afinado com as expectativas de Itaboraí do que com as orientações de Thiers ("o rei reina mas 
não governa”), Pedro II “imperava, governava e administrava” (p.111).

O capítulo ainda esclarece significados dessa "Conciliação" - "nem maioria conservadora nem vitória luzia" (Paraná); ou, o princípio do "equilíbrio" (Olinda); ou ainda, a determinação de Pedro II de "não favorecer facções" - princípios que possibilitaram Assembleias temporárias supostamente equilibradas. Apesar desse estreito controle, a reforma eleitoral que, no gabinete Ferraz, aprovou os "círculos com 3 deputados" tendo em vista reforçar a representação conservadora, deu resultados inesperados no escrutínio de 1860: “ainda não dá maioria aos liberais, mas permite a ida à Câmara de uma oposição numerosa e valente que daí por diante não haverá de poupar a mais poderosa entre as duas facções [a conservadora] que nunca cessaram, no fundo de contrapor-se, apesar do congraçamento de superfície" (p.69).

As limitações desse parlamentarismo sem autenticidade são desdobradas a partir do capítulo "Entre a Liga e o Progresso", o terceiro da primeira parte. Ao narrar as vicissitudes de Caxias e de seus sucessores para compor e preservar equipes de trabalho, e narrar a "dança de gabinetes" assistida entre 1862 e 1868 episódios que deram mais visibilidade ao grande alcance do poder pessoal - Buarque explicita a incompatibilidade entre as expectativas das Câmaras eleitas e gabinetes articulados segundo um entendimento de moderação fundamentado nas concepções políticas e, destacadamente, nas decisões do imperador. Explicita também as dificuldades dessa oposição parlamentar - arregimentada entre alguns liberais históricos e muitos conservadores dissidentes - em compor-se como "Liga" ou constituir um "terceiro partido" dotado de princípios e programa. Isso porque esbarrava na prevalência dos interesses pessoais dos membros que a integravam e no fato de a maior parte deles provir das hostes conservadoras, a exemplo de Zacarias que, naquele momento, "não achava que o país ainda precisasse de mudanças revolucionárias", de Nabuco de Araújo e Saraiva, dentre outros. Nesse sentido, "a liga, formada no Império de elementos oriundos de correntes políticas tradicionais [...] não podia, sem exagero, ser equiparada ao 'tiers-parti' que na França se embrenhou entre as tendências políticas nascidas da revolução de julho" (p.93).

Demonstrada a constância e o impacto das intervenções do poder pessoal nos rumos da "política de Conciliação", opinião reiterativa de críticas liberais e republicanas a essa ingerência, no capítulo "Por graça de Deus" o autor aproxima as figuras do imperador e do homem para reconhecer como "os traços distintivos da personalidade" e, especialmente, das "limitações pessoais" de Pedro II “marcaram fortemente a vida pública brasileira durante o meio século de seu reinado". Assim, "o patriotismo, a natural circunspecção, a sobriedade nas opiniões, o detalhismo nas avaliações, a morosidade nas reações, a recusa em favorecer facções, a capacidade de relevar ressentimentos e agravos em nome do interesse nacional" poderiam sugerir que "pairava acima das divisões e paixões políticas” e, em suas palavras, seguia normas do "parlamentarismo britânico". Porém, aquelas convicções efetivamente subvertiam os usos do sistema representativo, servindo apenas para dissimular que Pedro II "nunca aceitou tranquilamente a teoria de que a um rei constitucional, não pertence o exercício de governar", e que, 
segundo suas próprias palavras, "queria ser um supremo e vigilante inspector da coisa pública". Respaldado por dispositivos constitucionais, julgava-se desobrigado de apresentar suas razões" fossem elas "más ou boas", tornando assim um "fingimento a democracia praticada no império" (p.110).

Nessa medida, escolheu com constante determinação os presidentes dos gabinetes do Império, acompanhou de perto e com pacienciosa minúcia a atuação de seus ministros, tornou-se um meticuloso leitor e comentador dos relatórios e de todas as propostas políticas por eles apresentadas. Tal "excesso de zelo" resultou, invariavelmente, em dispersão nas tarefas e retardo no encaminhamento de reformas que ele mesmo considerava importantes para os negócios públicos e o país - como a da emancipação escrava, por exemplo - problema que, entretanto, não parecia preocupá-lo. Apesar de "confiar no futuro", no fundo, parecendo reprisar seu avô paterno, era um "fatalista": achava que as "coisas haveriam de resolver-se a seu tempo, convindo, evitar qualquer afoiteza” (p.134).

Buarque sublinha o quanto os traços pessoais de Pedro II reverberavam naquela maneira de exercer a administração pública, especialmente a ojeriza à lisonja, a aplicação, a perseverança, a pertinácia, a insaciável curiosidade, a atração pelo saber livresco, pelo conhecimento técnico e pelo estudo das línguas vivas e mortas. E desconfia da eficiência desse saber e da declarada identificação do imperador "com seu século e com a religião do progresso" porque se tratava de

erudição eminentemente livresca, adquirida sem dúvida com notável pertinácia, mas de forma desconexa e indisciplinada, como uma fruição dos sentidos. Desse saber extensivo e sem pouso certo, mal há de esperar no caso de Pedro II [...] que fosse operar qualquer transformação mental apreciável [...] o próprio progresso tal como o entende, não deixa de ser palavra equívoca e chega a trair, com freqüência um pensamento conservador $[. .$.$] por-$ que precipitar a colheita? [...] Ora, a meticulosa cautela deixa de ser virtude no momento em que passa a ser estorvo: lastro demais para pouca vela. (p.139-42)

A inesperada inversão política de 1868 interrompendo o $2^{\circ}$ Quinquênio Liberal - tão decepcionante para os liberais contemporâneos quanto para o intérprete dos acontecimentos - seria exemplar na demonstração desse conservadorismo, e daria início a um processo irreversível de desprestígio da figura do imperador e de descrédito no regime. A súbita transferência do poder dos "ligueiros progressistas", chefiados por Zacarias, para conservadores muito ortodoxos, seguida da dissolução da Câmara liberal hostil ao gabinete Itaboraí (tema tratado em $A$ crise do regime, capítulo único da parte II), denunciaria "a burla" que obscurecia a forte tendência retrogressiva da vontade imperial no jogo parlamentar e desvirtuava o sistema representativo nacional. À luz desse episódio, Buarque retoma os sentidos da Maioridade, marco da apropriação, pelo Executivo, do poder e direitos exercidos pela Câmara temporária no período regencial. Por sua vez, nos dois capítulos que compõem a terceira parte do livro, avalia as decorrências daquele sistema que permanecia cativo dos desejos de Pedro II. Nessa tarefa, prioriza os resultados da "dança dos gabinetes" que se desenrolou a partir de 1840, ou seja, a instabilidade política, outro motivo da 
demora nas reformas importantes para o país, como a da lei de 3 de dezembro de 1841 (que atrelara polícia e judiciário); a do recrutamento, que penalizava os trabalhadores assalariados; e a da questão servil. Razão também da inoperância da máquina administrativa provincial tendo-se em vista a incessante substituição dos presidentes e sua subordinação aos ministérios.

É ainda nos capítulos das segunda e terceira partes do livro que Buarque comenta os motivos do empenho de Pedro II em se orientar pelos modelos conciliadores europeus, assim como suas escolhas sempre conservadoras, e extrema cautela com os liberais a partir de 1848: receava uma repetição local dos acontecimentos revolucionários que, no final da década de 1840, haviam atingido muitos soberanos na Europa, vários deles seus parentes. Para Buarque, tal receio provinha, efetivamente, "da ilusão de ótica dos que buscavam a qualquer preço correspondentes indígenas de sucessos do velho mundo não tendo em conta a diversidade dos contextos históricos [...] Porque, $[\ldots]$ era irrisório querer procurar afinidades com a monarquia de julho francesa, por mais que fornecesse esta a muitos estadistas do Império seus modelos diletos". No que diz respeito a 1848 , observa que "quando muito pode-se dizer que as notícias de Paris, ecoaram aqui como um conselho de prudência que ajudou a prolongar ainda o predomínio liberal" (p.184).

Nesse sentido, interpreta a insistência do imperador e de vários políticos em escolher "modelos diletos" na Monarquia de Julho tão somente um "mimetismo que se instalou desde cedo em nossa existência política, onde vingavam os modelos estrangeiros, principalmente franceses, que parecessem tornar ilustres e respeitáveis os episódios da vida pública brasileira" (p.90). Pesquisando argumentos para esse procedimento, faz leitura singular da tese da repetição histórica como farsa divulgada por Marx no Dezoito Brumário: Pedro II seria uma "caricatura" de Luís Felipe de Órleans contemporâneo do reinado de Luís Felipe [...] muita coisa em todo seu comportamento pode fazer pensar em uma caricatura daquele juste milieu que celebrizou o mundo do rei-cidadão. Caricatura. Querer forçar muito mais a parecença é esquecer que o Brasil, além de conservar muito do passado colonial e depender largamente do trabalho escravo, não tinha banqueiros, nem riqueza mobiliária, a bem dizer, nem burguesia, que foram os principais suportes de Monarquia de Julho e de tudo o que ela representou. (p.140)

Reiterando matrizes teórico-metodológicas de variado perfil que fundamentaram inúmeros outros trabalhos do historiador (desde os modelos weberianos, passando pelos pais fundadores dos $A n$ nales e chegando ao uso pontual de textos de Marx), a proposição mais enfática desses Capitulos é comparar a experiência monárquica brasileira com versões modelares dos sistemas representativos europeus, inglês e francês notadamente, tanto para reforçar dessemelhanças entre as duas situações quanto para identificar a especificidade da monarquia aqui implantada que subordinou o "moderno" ao "arcaico", ou "combinou o princípio da 'sanção divina' com a 'unânime aclamação dos povos' ainda que de modo figurado ou simbólico" (p.187). Para Buarque, se havia circunstâncias nas quais o governo de Pedro II poderia se reconhecer, elas seriam encontradas apenas em seu próprio passado. Não por acaso, em 


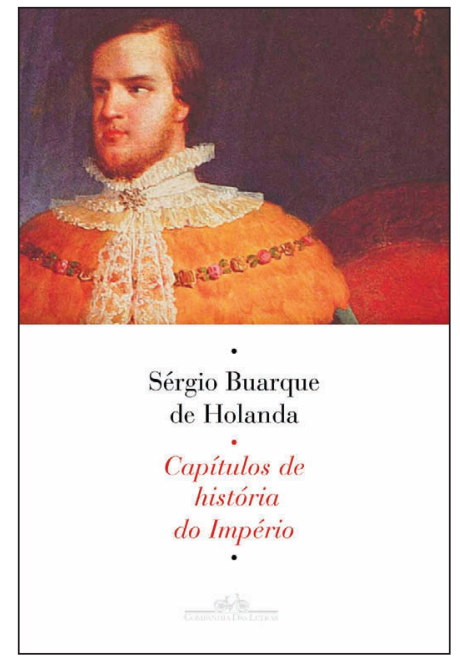

HOLANDA, S. B. de. Capitulos de história do Império. Organização de Fernando Antonio Novais.

São Paulo: Cia. das Letras, 2010.

análise retrospectiva, o autor estabeleceu um estreito diálogo entre os episódios de 1868, marco de desmascaramento do regime, com ocorrências das décadas anteriores, destacadamente o Quinquênio Liberal dos anos 1840 e seu desfecho, a inversão de 1848 .

Conforme já comentaram estudiosos da obra de Holanda, essa preocupação comparativa e explicativa o aproxima de outros "intérpretes do Brasil" de sua geração e do século XX - literatos, historiadores e intelectuais - que buscaram encaminhamentos para o país diversos tanto dos modelos europeus fascistas e comunista quanto do norte-americano. Assim, privilegiando a história, Buarque interpelou continuamente o passado monárquico para ali delinear eventuais rumos do que designara em Raizes do Brasil (1936) a "nossa revolução". Ou, como mencionou Fernando Novais na nota introdutória, o historiador retomou nesses Capitulos "a obsessiva indagação - entender por que nos sentimos desterrados em nossa própria terra", para a qual sinalizou em seus escritos (segundo analistas das diferentes edições de Raízes: 1936, 1948 e 1967), alternativas coerentes com suas orientações literárias, românticas e modernistas e com assertiva lançada naquela obra: o "paradoxo" de sermos, simultaneamente, "desterrados em nossa terra" e personagens de "experiência sem símile" e bem-sucedida nos trópicos.

A primeira alternativa sugeriu que nos sentimos "desterrados" porque, reprisando concepções e condutas conservadoras das elites que conduziram o Império e a República, reiteramos o apego às origens e à cultura europeias "transplantadas" pelos colonizadores e aos modelos políticos que nos chegaram daquele continente. A segunda: nos sentimos desterrados porque, uma vez preservada aquela postura, minimizamos situações históricas e fundamentos da sociedade aqui constituída, ou seja, o conjunto do país ao qual pertencemos seu povo, cultura, experiência sem similar que viabilizou a conquista, ocupação e organização do território, assim como os problemas remanescentes da colonização. Ou, nos termos de Novais, "as estruturas mais profundas do nosso modo de ser", referências basilares para visualizarmos "as possibilidades de modernização que nos reserva o futuro".

Com efeito, pelas inferências tangenciadas nesse trabalho inacabado, a expectativa de (re)conhecimento dos vestígios mais autênticos desta nação - aqueles remetidos à sua condição americana ou a uma formação social mais fluida, por vezes democrática, e sensivelmente di- 
versa das sociedades hierarquizadas do velho continente -, assim como da "revolução" a ser alcançada, não poderia prescindir do estudo bem informado e crítico de nosso passado colonial e monárquico. Assim, Sérgio Buarque dedicou parte significativa de sua obra e percurso intelectual a essa tarefa.

Inspirando-se, de início, em Capistrano e outros críticos das visões "elitistas" da história brasileira, e depois alargando sensivelmente suas referências, (re)interpretou, por exemplo, as realizações das bandeiras e os sentidos imbricados na opção pela independência, na abdicação, nos confrontos do período regencial, na "valente" oposição das Câmaras aos gabinetes moldados segundo a vontade imperial e no desempenho de políticos liberais "íntegros" que não teriam se deixado seduzir pelos condutores da "Conciliação", a exemplo de Paula Souza e José Bonifácio, o moço. Dessa forma, a constante e enfática certeza sobre a sobrevivência de uma herança opressiva das elites coloniais no Império e na República, destaque nas teses do historiador, teve sempre por pressuposto o embate entre forças autenticamente inovadoras e permanências do passado, ou entre "o moderno e o arcaico", premissas que esses Capitulos preparados nos últimos momentos de reiterativa $\mathrm{e}$ consequente busca das "raízes" do Brasil também deixam entrever.

Izabel Andrade Marson é professora colaboradora do Departamento de História da Universidade Estadual de Campinas. @ - iamarson@unicamp.br 